\title{
CLINICAL USES OF 2,3-DIMERCAPTOPROPANOL (BAL). VIII. THE EFFECT OF BAL ON THE EXCRETION OF ARSENIC IN ARSENICAL INTOXICATION ${ }^{1}$
}

\author{
By JOHN A. LUETSCHER, JR., HARRY EAGLE, AND WARFIELD T. LONGCOPE \\ WITH THE TECHNICAL ASSISTANCE OF EMILY B. WATSON \\ (From the Venereal Disease Research Laboratory of the United States Public Health Service \\ and the Department of Medicine, Johns Hopkins University and Hospital, Baltimore)
}

(Received for publication February 5, 1946)

The toxic effect of arsenic on the living cell probably follows the combination of the arsenic with certain vital components of the cell ( 1 to 5 , 8). This combination has been observed to be reversible in vitro ( 5 to 9 ). With the development of 2,3-dimercaptopropanol (BAL) by Peters, Stocken, and Thompson (8), the detoxification of arsenic by dissociation of the arsenic-cell complex seemed feasible in man, since BAL has the requisite affinity for arsenic without undue toxicity ( 8 to 10$)$. BAL was therefore administered in ointment, and later by injection, in the treatment of arsenical intoxication $(11,12)$.

An increased elimination of arsenic from the body during BAL treatment would probably reflect the release of a significant amount of arsenic from the cells $(8,10)$. To test this point, the urinary excretion of arsenic has been followed before and during treatment with $\mathrm{BAL}$ in 18 patients in this clinic. Sixteen were suffering from a complication of arsenical therapy. The effect of BAL on these patients' course is described in another report (11). The other 2 patients, who had received mapharsen without untoward reaction, were studied to determine the effect of BAL administered 2 and 3 days after an injection of the arsenical drug. The effect of BAL on the fecal excretion of arsenic was not followed, since the brief control period and the illness of the patients prevented the collection of accurately timed speciments.

\section{METHODS}

Arsenic in the urine was determined by the method of Magnuson and Watson (13).

1 Part of the work described in this paper was done under a contract, recommended by the Committee on Medical Research, between the Office of Scientific Research and Development and the Johns Hopkins University.
For inunction, BAL was added in 5 or 10 per cent concentration to an ointment containing benzyl benzoate in an oily base. This ointment was devised by Mr. R. S. Fuqua and tested by Dr. W. F. Hughes, Jr., in Lewisite burns of the eye (14). BAL was given intramuscularly in 5 or 10 per cent concentration in peanut oil and benzyl benzoate (10).

Urinary sulfur was measured by the gravimetric procedures of Folin and Benedict (17).

The titration of urine with iodine was performed at a strongly acid reaction. Approximately 1 volume of concentrated $\mathrm{HCl}$ was added to 5 volumes of urine, and the mixture quickly titrated with $0.01 \mathrm{~N}$ iodine solution. Speed of titration was emphasized, since the urine may take up excess iodine slowly. A trace of freshly prepared starch solution was used as an indicator. Highly concentrated urine gave a poor end-point, and was diluted suitably. Duplicate or triplicate measurements were made. BAL added to urine could be measured by the procedure, but the reaction is obviously not specific for BAL. The results are presented to indicate the increment of reducing substances, including reduced sulfur, which accompanies the use of BAL.

\section{RESULTS}

Eight patients with arsenical dermatitis were given BAL by inunction or injection. In every case, there was an increase in arsenic excretion following the first course of BAL treatment (Table I). Four patients received a second course of treatment, with an increase in urinary arsenic in each case (Table I, Figures 1, 2, and 3). One of these patients, after responding to 2 series of BAL injections, showed an increased excretion of arsenic following a 3-days course of inunction with $\mathrm{BAL}$ in ointment, but gave no clear response to a subsequent single, large inunction (Figure 3 ). The total courses of treatment numbered 14 in 8 patients, with increased arsenic excretion in 13 trials in 8 patients.

In contrast to the findings in dermatitis, only 3 of the 6 patients with jaundice showed an increased excretion of arsenic after a course of 
BAL AND EXCRETION OF ARSENIC IN ARSENICAL INTOXICATION

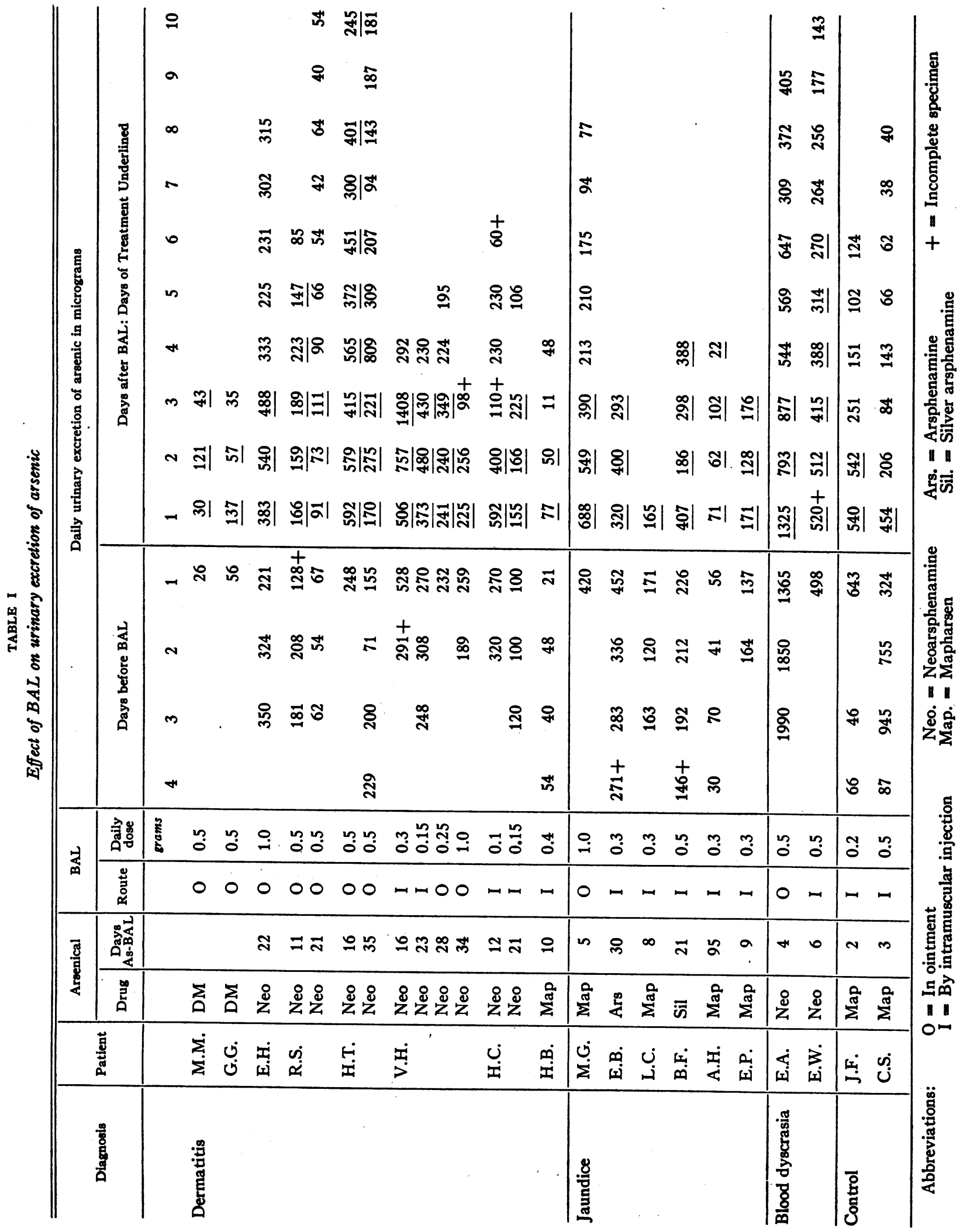




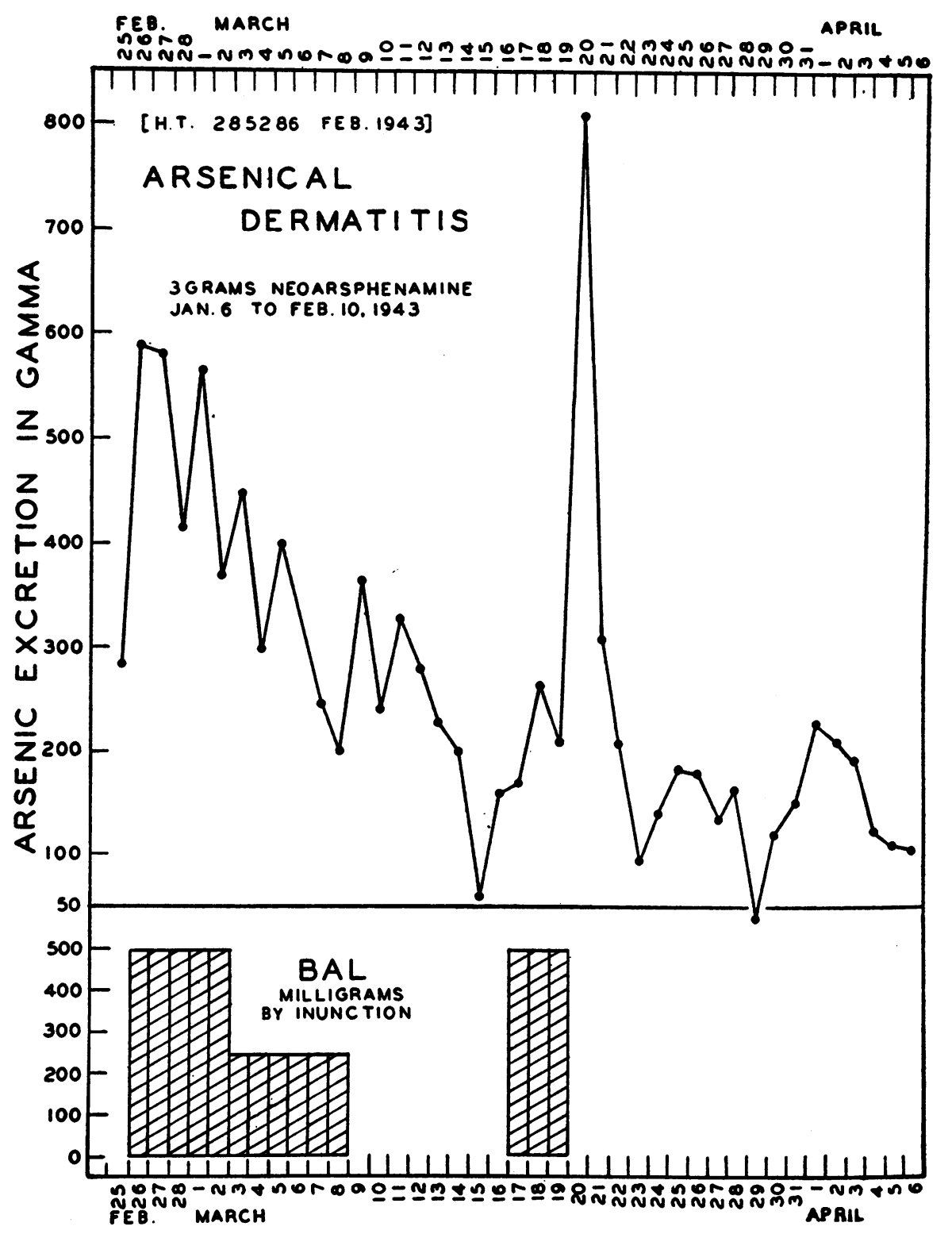

Fig. 1. Effect of Two Courses of Inunction of BAL Ointment on Daily Arsenic Excretion in Arsenical Dermatitis (Patient H. T.)

BAL treatment. In the whole series of cases, all of the obvious failures of increased excretion were in cases of jaundice occurring during antisyphilitic treatment.

The 2 patients with agranulocytosis and thrombocytopenia entered the hospital within a few days of the last injection of arsenic, when the rapidly decreasing excretion of arsenic made the effect of BAL treatment difficult to demonstrate. In 1 patient (E. W.) there was possibly a small in- crease in urinary arsenic after treatment, but in the other (E. A.), no effect was evident. In order to study a similar situation with adequate control observations in patients without a pressing need of treatment, 2 men under antisyphilitic treatment were given $\mathrm{BAL}$ by intramuscular injection 2 or 3 days after the last arsenical injection. The results (Figure 5) were very similar to those seen in the patients with blood dyscrasia. During the period of rapidly decreasing arsenic 


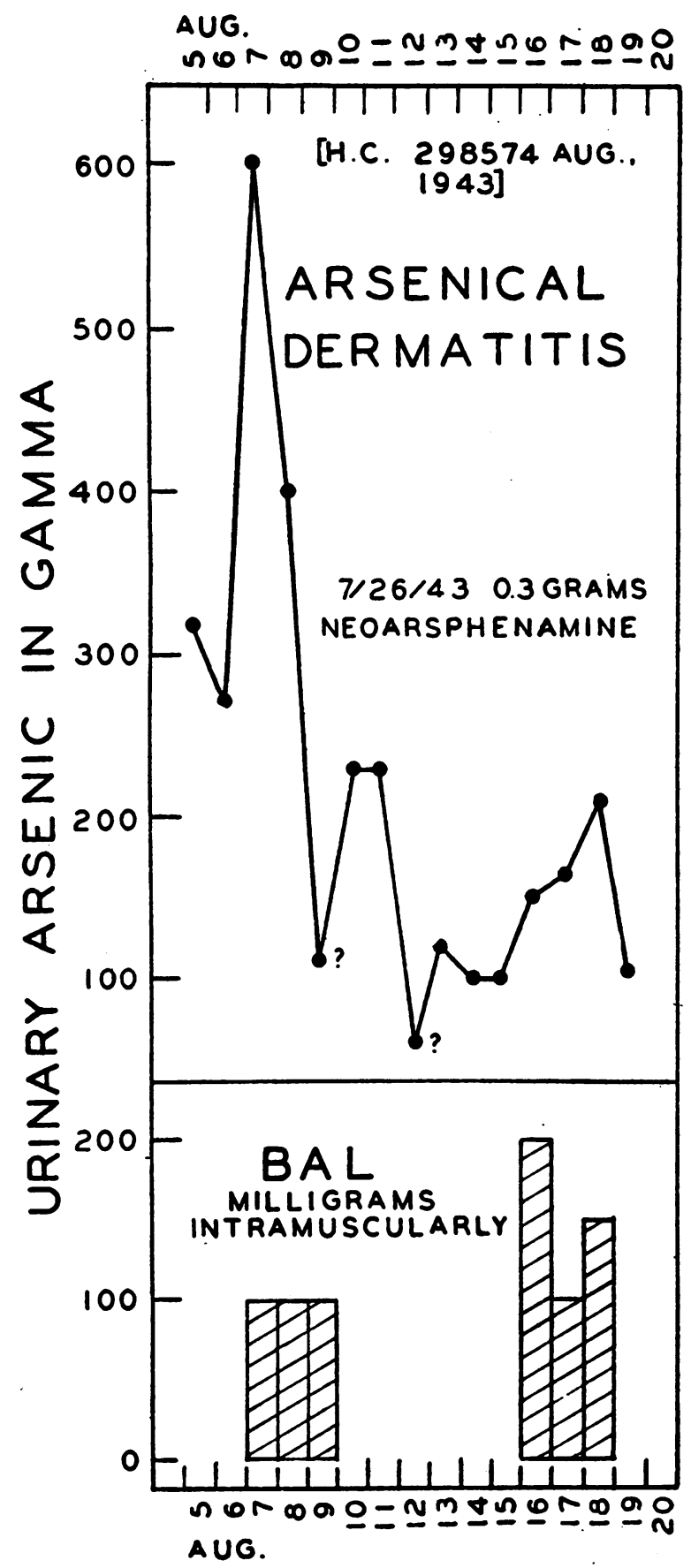

Fig. 2. Effect of Two Series of Intramuscular Injections of BAL on Daily Arsenic Excretion in Arsenical Dermatitis (Patient H. C.)

excretion, little or no increase of urinary arsenic was observed after BAL, but a rapid fall in arsenic excretion might be noted at the end of treatment.
The effect of the route of administration of BAL on the excretion of arsenic cannot be evaluated because of the small number and diversity of the cases. It is evident that either inunction or injection of BAL is generally quite effective. The dosage by inunction was usually larger.

A few experiments were undertaken to observe the relation between urinary sulfur and arsenic during the administration of BAL. In 3 patients, excretion of organic sulfur increased after BAL (Figures 4 and 5). In each case, the excretion of arsenic was affected to a greater or less degree by the administration of BAL, and the change coincided with an increase of organic sulfur in the urine. The reverse effect could not be demonstrated in 2 cases (Figure 5) in which an injection of mapharsen did not appreciably affect the excretion of organic sulfur.

As a rough measurement of the addition of reduced sulfur to the urine after the administration of BAL, the iodine uptake of strongly acidified urine was measured. This quantity, recorded as $\mathrm{m}$. eq. of iodine per day, increased after BAL treatment and closely followed the changes of arsenic excretion in 2 cases (Figures 4 and 6).

\section{DISCUSSION}

The consistent increase in arsenic excretion after BAL treatment of arsenical dermatitis corresponds with the good clinical response of these patients (11). Although it is apparent that some arsenic is removed by the BAL, the excretion of arsenic continues at a lower level after the completion of treatment. There are reasons to believe that the arsenic removed by BAL is that which is most damaging. The combination of the skin with highly toxic arsenicals has been demonstrated to be reversible by $\mathrm{BAL}(8,9)$. BAL has been shown to restore cellular ferments of the skin inactivated by toxic arsenicals $(8,9)$. Furthermore, the most toxic arsenical compounds, which are bound most firmly to the living cell, show the greatest stimulation of excretion after BAL (3, 10). These observations suggest that the increase in urinary arsenic after BAL treatment reflects the release of a toxic arsenical from the skin, with consequent improvement of the dermatitis.

No such regular improvement is evident, either 


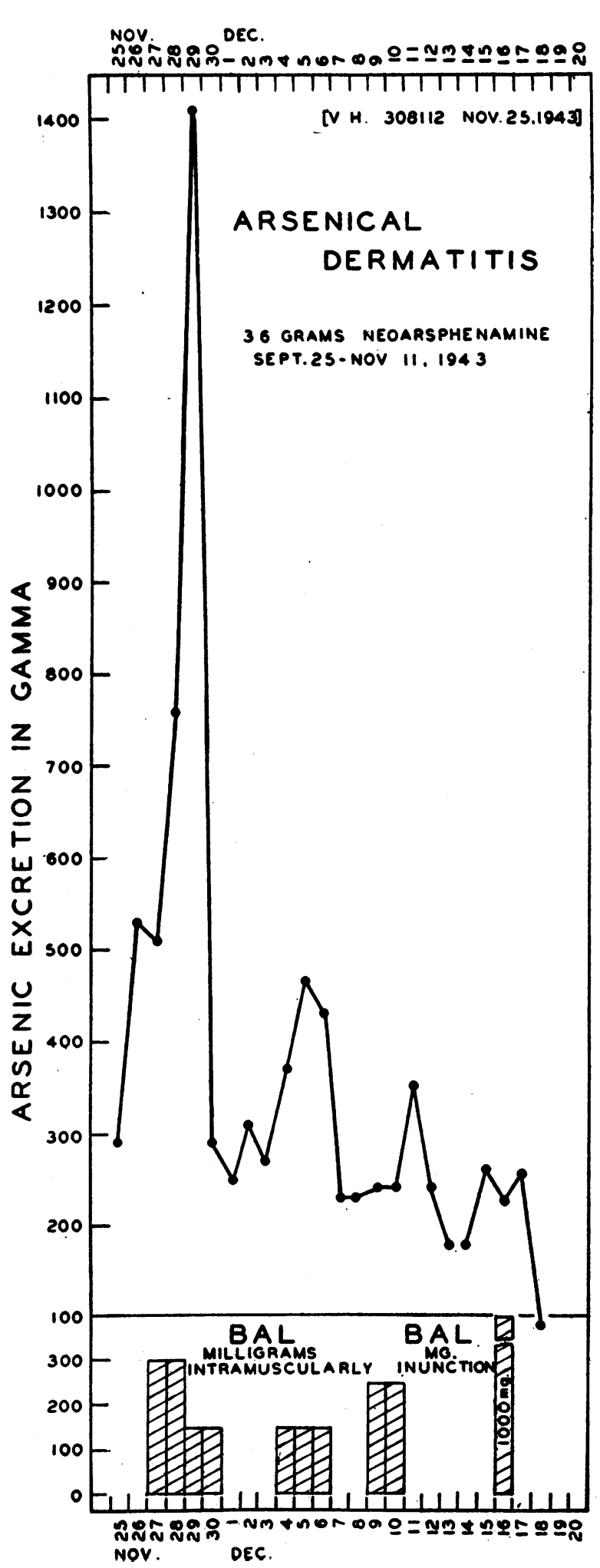

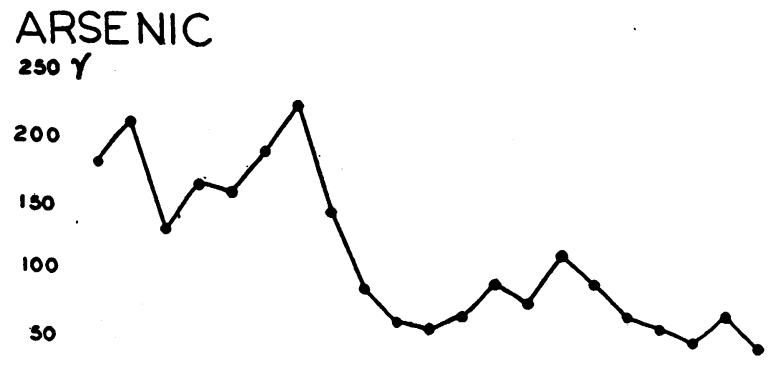
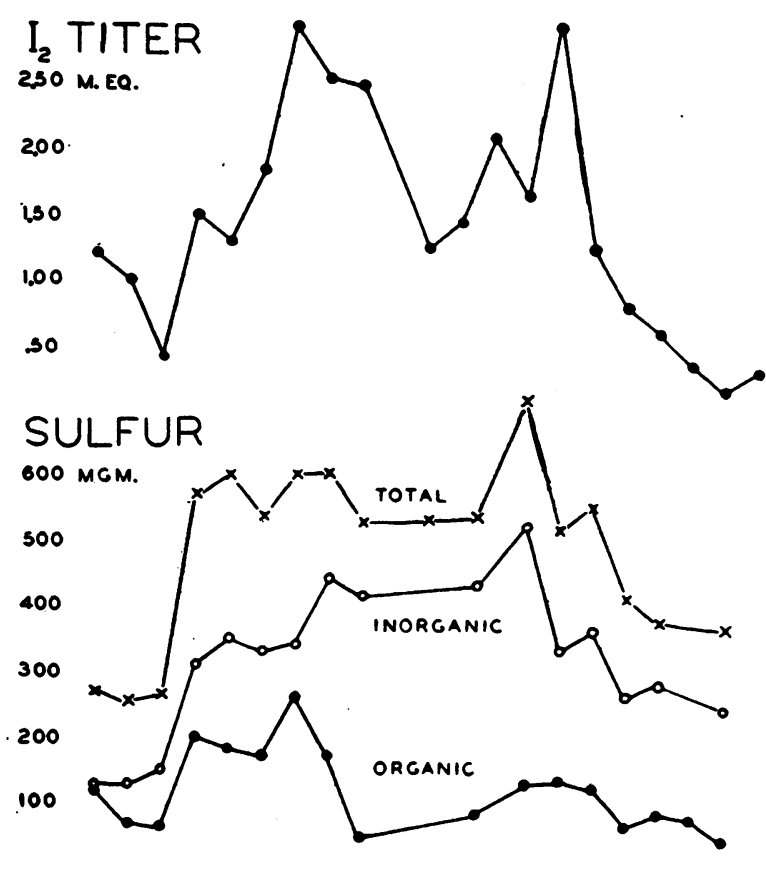

500 MGM.

$B A L$
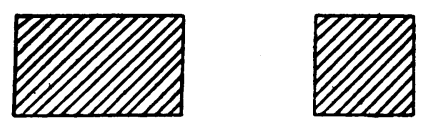

Fig. 4. Daily Urinary Excretion of Arsenic, Iodine-titrable Reducing Substances, and Sulfur (OrgaNic, INORganic, AND TOTAL, INCLUding Ethereal) During Two Courses of Treatment of Arsenical Dermatitis with Inunctions of BAL (Patient R. S.)

clinically or in the excretion of arsenic after BAL treatment, of the jaundiced patients. The arsenic excretion was unchanged in 3 cases, and moder-

Fig. 3. Effect of BAL on Daily Arsenic Excretion in a Patient with Arsenical Dermatitis (PaTIENT V. H.)

The patient received 2 courses of intramuscular injections of BAL. Subsequently, she was given a brief course of inunction with BAL in ointment and finally a single large inunction. 
ately increased in the other 3. It is difficult to assess the etiologic rôle of arsenic in these cases, since intercurrent hepatitis would produce much the same picture (15). Moreover, the type of jaundice produced by arsenical drugs varies (16), and BAL might not be expected to affect each type equally. The phosphatase activity as a measure of biliary obstruction shows no correlation with the response to BAL.

The increased excretion of organic sulfur and reducing substances after the administration of BAL coincides with the increase in urinary arsenic. Considering the large excess of sulfur, it seems improbable that an increased urinary arsenic could affect appreciably the excretion of organic sulfur, and no such effect is evident. These observations support the idea that the administration of BAL promotes the excretion of arsenic by supplying an excess of material with which arsenic forms stable compounds.

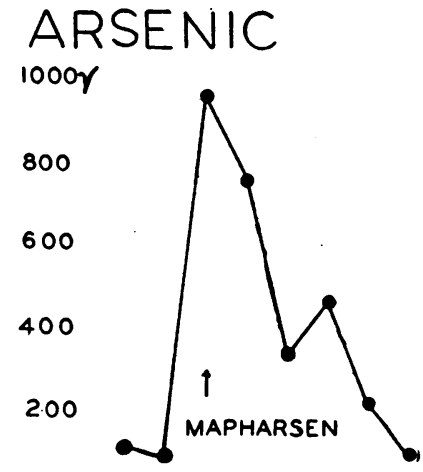

SULFUR

ORGANIC

300 MGM.

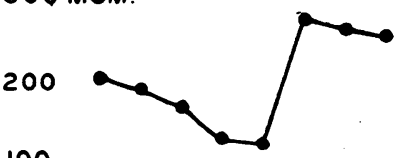

100

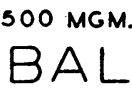

200

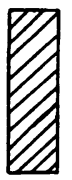

Fig. 5. Daily Urinary Excretion of Arsenic and Organic Sulfur in Two Patients (C. S., Left, and J. F., Right) Receiving Mapharsan Followed after 2 to 3 Days by Intramuscular InJection of BAL

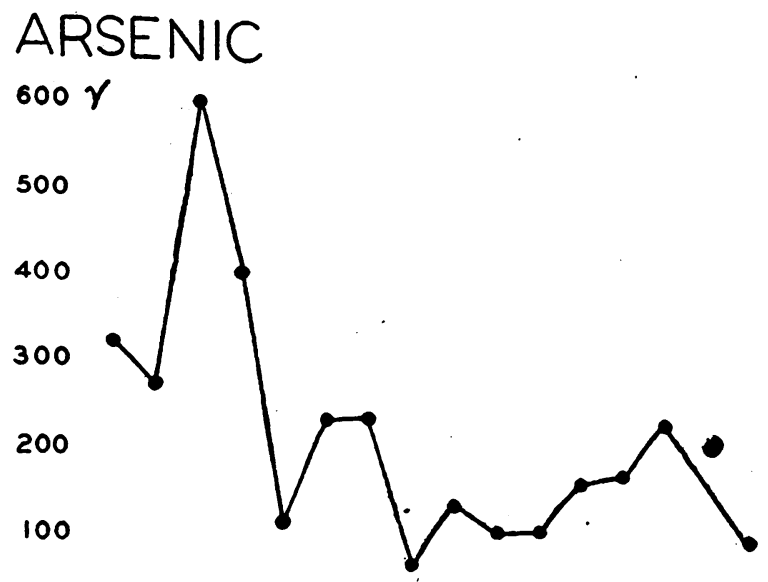

$I_{2}$ TITER

6 MEQ.
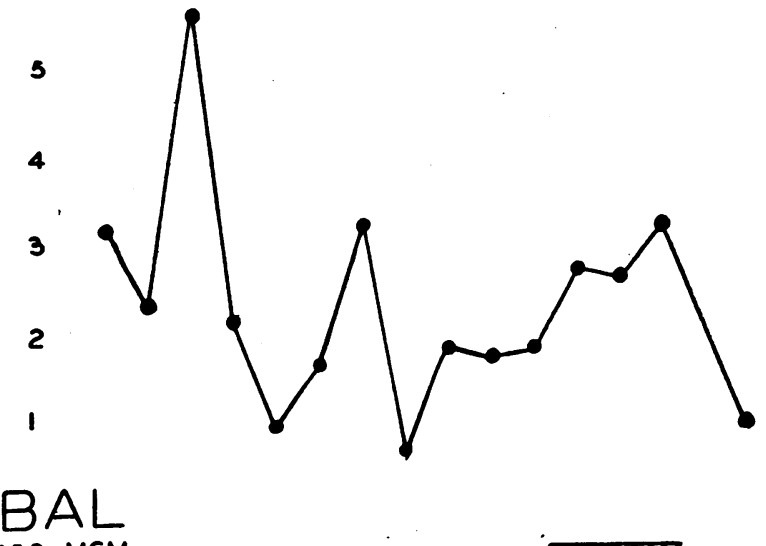

150 MGM.

100
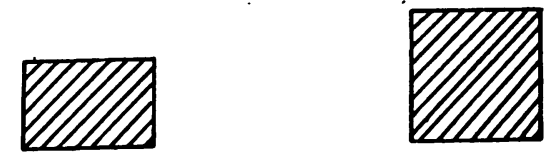

Fig. 6. Daily URinary Excretion of Arsenic AND Iodine-titrable Reducing Substances During Two Courses of Treatment of Arsenical Dermatitis with Intramuscular Injections of BAL (Patient H. C.)

\section{SUM MARY}

The urinary arsenic has been studied before and after BAL therapy in 16 patients with arsenical intoxication, and in 2 patients receiving arsenical treatment without reaction. Of 24 courses of BAL administration, 16 were followed by a definite increase in arsenic excretion, 4 by a possible increase, and 4 by no increase. On no occasion was there a decreased excretion of arsenic during BAL treatment. 
The increase in urinary arsenic after BAL appears to be more consistent in patients with the arsenical dermatitis than in hepatitis, suggesting a correlation with the greater efficacy of BAL in the treatment of arsenical dermatitis.

The increases of urinary organic sulfur and reducing substances coincide with the increased urinary arsenic after BAL administration, lending support to the idea that the excretion of BAL or a related substance is associated with the increased arsenic excretion.

\section{BIBLIOGRAPHY}

1. Walker, E., Chemical constitution and toxicity. Biochem. J., 1928, 22, 292.

2. Rosenthal, S. M., Action of arsenic upon the fixed sulphydryl groups of proteins. Pub. Health Rep., 1932, 47, 241.

3. Hogan, R. B., and Eagle, H., The pharmacological basis for the widely varying toxicity of arsenicals. J. Pharmacol. and Exper. Therap., 1944, 80, 93.

4. Eagle, H., and Magnuson, H. J., The spontaneous development of arsenic-resistance in Trypanosoma equiperdum, and its mechanism. J. Pharmacol. and Exper. Therap., 1944, 82, 137.

5. Barron, E. S. G., and Singer, T. P., Enzyme systems containing active sulfhydryl groups. The role of glutathione. Science, 1943, 97, 356.

6. Eagle, H., The effect of sulfhydryl compounds on the antispirochetal action of arsenic, bismuth, and mercury compounds in vitro. J. Pharmacol. and Exptl. Therap., 1939, 66, 436.

7. Eagle, H., The toxicity, treponemicidal activity, and potential therapeutic utility of substituted phenyl- arsenoxides. I. Methods of assay. J. Pharmacol. and Exper. Therap., 1940, 69, 342.

8. Peters, R. A., Stocken, L. A., and Thompson, R. H. S., British Anti-Lewisite. Nature, 1945, 156, 616.

9. Waters, L. L., and Stock, C. C., BAL (British AntiLewisite). Science, 1945, 102, 601.

10. Eagle, H., Magnuson, H. J., and Fleischman, R., The systemic treatment of experimental arsenic poisoning (mapharsen, Lewisite, phenyl arsenoxide) with BAL. J. Clin. Invest., 1946, 25, 451.

11. Longcope, W. T., Luetscher, J. A., Jr., Wintrobe, M. M., and Jäger, B. V., The treatment of arsenical dermatitis with preparations of BAL. J. Clin. Invest., 1946, 25, 528.

12a. Eagle, H., and Magnuson, H. J., The systemic treatment of 227 cases of arsenic poisoning (encephalitis, dermatitis, blood dyscrasias, jaundice, fever) with 2,3-dimercaptopropanol (BAL). Am. J. Syph., Gonor., \& Ven. Dis. (in press).

b. Eagle, H., The systemic treatment of arsenic poisoning with BAL (2,3-dimercaptopropanol). Ven. Dis. Inform., 1946, 27, 114.

13. Magnuson, H. J., and Watson, E. B., Micro determination of arsenic in biological materials. Indust. Eng. Chem., Anal. Ed., 1944, 16, 339.

14. Hughes, W. F., Jr., Treatment of Lewisite burns of the eye with BAL. J. Clin. Invest., 1946, 25, 541.

15. Moore, J. E., The Modern Treatment of Syphilis, 2nd ed., p. 119, Charles C. Thomas, Springfield, III., 1941.

16. Hanger, F. M., Jr., and Gutman, A. B., Postarsphenamine jaundice apparently due to obstruction of intra-hepatic biliary tract. J. A. M. A., 1940, 115, 263.

17. Peters, J. P., and Van Slyke, D. D., Quantitative Clinical Chemistry. Vol. II. Methods. The Williams and Wilkins Co., Baltimore, 1932. 